\title{
Benchmarking Inter-Organizational System Architecture of Trade Facilitation in Singapore, Hong Kong, Netherlands and USA
}

\author{
Sita A. Sholihah, Senator Nur Bahagia, Andi Cakravastia, and TMA A. Samadhi
}

\begin{abstract}
In the context of exporting goods, hinterland activities are as important as port activities, including preparing export documents. Moreover, congestion frequently occurs both inside and outside seaport with flow of goods and information involving several actors from business entities and government agencies whose activities are interdependent. This paper studies the benchmarking of inter-organizational system (IOS) architecture in selected countries, in order to identify trade facilitation in international trade (export) via inland container terminal as spoke. This study revealed IOS' coordination architecture in preparing documents, custom clearance and inspections, and inland transportation and handling.
\end{abstract}

Index Terms - Inter-organizational system, international trade, single window, trade facilitation.

\section{INTRODUCTION}

There are two general activities in maritime logistics' chain: drayage operation which is a short haul operations in hinterland side, and line-haul operations or long-haul in sea side. In the context of exporting goods, hinterland activities are as important as port activities. Hinterland activities start when shipper (exporter/manufacturer) makes a contract export with importer, preparing goods, contact a forwarding company to help transporting the goods from warehouse until the goods arrive in container yard of seaport or dryport, including preparing its export documents. However, conventional clearance processes (paper-based) add as much as $10 \%$ to the product cost and lead to delays and penalties [1] Moreover, cost of hinterland transport is about $40 \%$ of total container transport cost [2]. So, in order to enhance competitiveness, trade facilitation is needed to simplify process and to minimize transaction cost in trading across border by simplifying procedures and associated information flows required to move goods from seller to buyer [3].

Trade facilitation is comprised of three main parts: (1) physical infrastructure that deal with flow of goods; (2) customs and borders administrative processes, transport formalities, tariffs and the application of trade laws and regulation; and (3) use of information and communication technologies (ICT) to harmonize and standardize trade procedures among countries and among all stakeholders involved in international trade [4].

Manuscript received July 30, 2017; revised October 19, 2017.

The authors are with the Department of Industrial Engineering, Bandung Institute of Technology, Bandung, Indonesia (e-mail: avec_sita@ yahoo.com, senator@mail.ti.itb.ac.id, andi@mail.ti.itb.ac.id, asamadhi@mail.ti.itb.ac.id).
Congestion frequently occurs both inside and outside seaport, and hamper flow of goods. Therefore, to support goods movement from and to international hub port, it necessary to have spokes as physical infrastructure that serve as extended gates of seaport (hub). Spoke is also a place for consolidation and distribution of goods and an intermodal connection which is directly integrated with hub port. Spoke can be an inland container terminal (ICT) or dryport Hub-and-spoke network reduce the number of point-to-point direct loads that under-utilized [5]. As a result, load factors are increased and total operating costs are reduced [5], [6].

Moreover, hinterland chain of export via spoke involves several actors from business entities and government agencies. Each actor involved have their own roles and activities that are interdependent. So, quality of hinterland access depends on the behavior of the actor involved in it [7]. If coordination among actors is not good, it will affect the smoothness of exporting goods. Thus, it needs institutional frameworks and deliberative mechanisms, harmonization and simplification of business processes.

Many studies have been addressing the important component in trade facilitation [4], [8]-[10], usage of trade facilities in several countries [11]-[13], transparency in international trade [4], and drivers and barriers affecting usage of e-Government/e-Customs [14], reduction of trade cost [15]. However, no one has described linkage between stakeholders involved. Meanwhile, researchers in the field of inter-organizational systems (IOS) stated that the management of interdependence is a key concept in the understanding and formulation of the role of information technology [16].

This paper will benchmark inter-organizational system of trade facilitation in several countries that already implement it. Selection of countries are based on performance of export process, similarity of hinterland characteristics with Indonesia (archipelago country), and exporting agricultural or animal products. Based on this selection criteria, the benchmark countries are Singapore, Hong Kong SAR - China, Netherlands and USA. Section II gives explanation about the concept of inter-organizational system and coordination. Section III benchmark IOS architecture of selected countries. Section IV analyzes IOS architecture, while Section V gives conclusion.

\section{LITERATURE REVIEW}

There are various definitions of trade facilitation. Based on World Trade Organization (WTO), trade facilitation is "The 
simplification and harmonization of international trade procedures, where trade procedures are the activities, practices, and formalities involved in collecting, presenting, communicating, and processing data and other information required for the movement of goods in international trade." The purpose of trade facilitation is to improve the efficiency of the processes associated with trading across border by simplifying procedures and associated information flows required to move goods from seller to buyer, thus it effect on minimizing trade transaction cost [3], [17].

In term of rules and procedures of export through inland container terminal (ICT), there are several actors involved both from business entities and government agencies (GA). These actors have their own roles and activities that interdependent, such as shared resources (e.g. information, equipment, etc.), prerequisites, and simultaneity constraints. Responsibility of each actor can be seen in Table I.

TABLE I: RESPONSIBILITY ACTOR

\begin{tabular}{ll}
\multicolumn{1}{c}{ Actor } & \multicolumn{1}{c}{ Responsibilities } \\
\hline \hline $\begin{array}{l}\text { Shipper/ } \\
\text { exporter }\end{array}$ & - Creating export contract with consignee \\
& - Creating contract (order) of export shipment with \\
& Forwarder \\
& - Determine the readiness schedule of shipping goods \\
& to ICT/dryport \\
\hline Consignee & - Creating export contract with shipper \\
& - Applying document Letter of Credit (L/C) to Bank \\
\hline Forwarder & - Mediator of schedule information (vessel, train, and \\
& shipment goods to ICT/dryport) \\
& - Preparing export documents \\
\hline Trucking & - Generating truck-job-order \\
\hline Empty Depo & - Preparing MT container \\
\hline Railway op. & - Train scheduling \\
\hline ICT op. & - Time scheduling of goods receipt in ICT/dryport. \\
& - Mediator vessel schedule information to the railway \\
\hline Seaport op. & - Issuing enter permit to seaport \\
\hline Quarantine & - Physical and document inspection \\
\hline Trade Ministry & - Issuing Phytosanitary Certificate \\
\hline Customs & - Issuing Certificate of Origin \\
\hline Insurance co. & - Issuing insurance of goods \\
\hline Bank & - Issuing Letter of Credit \\
\hline & - Issuing other document (if required) \\
\hline &
\end{tabular}

In terms of communication and information system based on inter-enterprises technology, researchers in inter-organizational system (IOS) stated that managing interdependence is a main concept in understanding and formulating role of information technology [16]. By definition, IOS is an information system which connects one or more enterprises/organizations and facilitates the exchange of products and services Bakos in [18]. Area of IOS is broader than just the information exchange between actors in supply chain. Here, IOS has potential for deployment of information systems that support in collaboration of product development, process control, or other knowledge sharing.

Some researchers in IOS identified how organizations interact in term of managing their interdependent activities. Kumar and Van Dissel [16] stated that there are three ways in which organizational units depend on each other, i.e. centralized dependency, sequential dependency, and reciprocal dependency. Centralized dependency happens when some units of the organization use and divide same resources. Sequential dependency happens when output of a unit become input of another unit. Reciprocal dependency happens when some units use input-output for their activity in which are result from back and forth interaction between them. In this typology, each unit receives input from one and produces output to the other, interactively.

Based on transactional backbone, Lang et al. [18] stated that there are four types of architecture in connecting inter-organizational activities:

TABLE I: TYPE OF IOS ARCHITECTURE

Descriptions
- Point-to-point (P2P) relationship between
two separate systems
- A direct relationship between two business
partners
- The most basic form of relationship
- Works well for an important relationship
- Too expensive for connecting P2P two small
business partners.
Private hub (1:N)

\section{BENCHMARK OF IOS ARCHITECTURE}

The export's business process consist of several activities that generally can be divided into four groups of activities: documents preparation, custom clearance and inspections, inland transportation and handling, and port and terminal handling [19]. Here hub-and-spoke network is considered, where ICT or dryport as as spoke and seaport as a hub. ICT or dryport is an extended gate of seaport, where all facilities of seaport are also on ICT/dryport, including border clearance. So, when container is entering gate-in of ICT/dryport as port of departure, then it is already considered export. So, in this paper will exclude port and terminal handling activity.

\section{A. Singapore}

Singapore's hinterland is a whole country which consists of several FTZs (Free Trade Zone), where FTZs are exporter's warehouses. For drayage activities, stuffing goods is conducted in FTZ then it send directly to seaport. Here, functionality of FTZ is a place of goods consolidation and 
customs area. Type of Singapore's IOS architecture for international trade is centralized, in which each actor coordinate through a single window called PortNet. PortNet consist of several applications: Cargo D2D, TradeNet, Haulier Community System, and other supporting business application (see Fig. 1).
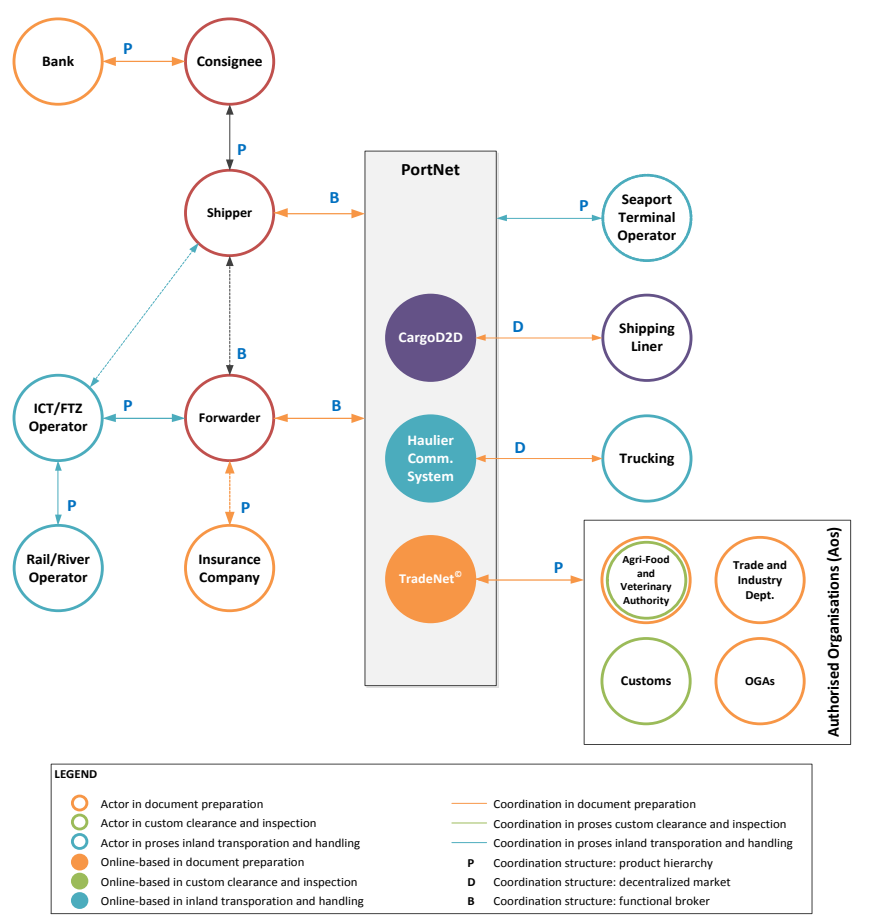

Fig. 1. IOS Architecture of Singapore.

CargoD2D serve shipping community in Singapore, in which all activities involving shipping liner, port, etc., can be done through CargoD2D. TradeNet serve document exchange in term of business-to-government (B2G), in which all government agencies (GA) as authorized organizations will communicate with shipper/exporter/ forwarder through TradeNet application. Haulier Community System (HCS) serve haulier community (trucking's), in which all activities involving drayage freight services can be done through HCS.

In $\mathrm{B} 2 \mathrm{G}$ document preparation process, user communicate with GA through TradeNet in PortNet system. Here, each user will have a unique entity number (UEN) which can be used to communicate with all GA. So, user only have to input the data once or single submission, therefor there is no duplication in inputting and archiving data. It also ease coordination between GAs (if necessary) because the data is synchronized accurately.

In customs clearance and inspection process, it applied TradeFirst System which stands for Trade Facilitation and Integration, Risk-based System. TradeFirst is a framework used by Customs to check thoroughly and provide facilitation to a company which is divided into five classes, namely: Basic, Standard, Intermediate, Enhance and Premium. The assessment criteria in provision of Customs facilities are: (1) company profile (general and financial profile), (2) inventory management and controls, (3) track record of request and its fulfillment, (4) process and procedure in handling freight and cargo, and (5) security. Because of almost all shipper's or forwarder's warehouse is a FTZ, then warehouse is Customs area, where the five classes of company distinguish amenity in terms of customs.

In customs clearance, documents are submitted through TradeNet before ship departure, except for strategic goods are 5 days before shipment. Response from the system will be received by shipper/forwarder electronically via TradeNet within 10 minutes after submitting. Container security system use e-Seal, so when seal is broken or container is not in the route, system will send information directly to Customs and real time. Meanwhile for CIQ, inspection/control of goods are performed regularly by Agri-Food and Veterinary Authority (AVA) - Quarantine \& Inspection Department. So when users apply for export, they only need to submit for Phytosanitary/Veterinary Certificate.

In inland transportation and handling, all processes are performed through Haulier Community System (HCS) in PortNet. HCS consist of trucking companies who collaborate in managing inland transport activity (drayage). All trucking companies act as if they are a single company under the HCS, where truck assignment is done through HCS. HCS system includes tracking and tracing (TnT) system and pre-notification of arrival in ICT and seaport that is applied very strictly. Thus, it can reduce driver time in terminal. Meanwhile, inspection of compatibility between goods and its documents is carried out during Gate-In inspection in ICT or seaport, where physical inspection is conducted using X-Ray.

\section{B. Hong Kong}

Port of Hong Kong is a seaport which is used as a hub in Hong Kong SAR, with its hinterland is Hong Kong SAR and Guangdong SEZ (special economic zone which accounts for the largest GDP in China). Type of ICT in Hong Kong is dryport. Each actor involved coordinate via three logistics service provider appointed by government: TradeLink, Ge-TS, and Brio. The providers act like single window in Singapore, but this kind of mechanism help in minimizing monopoly and increasing competitiveness in price and services. An overview of IOS architecture in Hong Kong can be seen in Fig. 2.

In preparation of $\mathrm{B} 2 \mathrm{~B}$ and $\mathrm{B} 2 \mathrm{G}$ documents, user communicate with all partners and GA through appointed providers (Ge-TS, TradeLink and Brio), where all documents are shared electronically. Inputting data only need to do once, then the data will be used in processing document in all GA and other stakeholder, so there is no duplication in inputting and archiving data. It ease coordination, because there is information sharing between GA and other stakeholders. Releasing permits is done electronically (e-Doc/e-Cert). Here, e-Cert will be transferred government-to-government (G2G) for fast and secure transfer (prevent counterfeiting document).

In customs clearance and inspection process, all documents are submitted through appointed providers. Here, inspection by Quarantine is conducted before customs declaration. Quarantine inspection is carried out based on list of inspection has been done previously by factory and requirement by export destination country. Here, Quarantine inspect samples to validate the treatment of goods. If it is not appropriate, then Quarantine will perform additional treatment. In customs clearance, export declaration is submitted through provider (Ge-TS/TradeLink/Brio) addressed to Commissioner of Customs and Excise via e-ACI (electronic Advance Cargo 
Information) and connected to data of ROCARS (Road Cargo System). Physical inspection is done by scanning. Along with physical inspection, customs will check the document. If everything is match, then customs will release export declaration electronically. Data on export declaration is connected with ROCARS and uses 11 data from ROCARS: Consignee's name, Consignee's address, Container Number, Goods Description, Type of Packages, Number of Packages, Quantity of Goods, Unit of Quantity, Vehicle Registration Number, Customs Cargo Reference Number (CCRN), dan Unique Consignment Reference (UCR). If the data does not match with ROCARS, then user must request change of export declaration.

In transportation and handling process, arrangement of inland transportation is done by forwarder, this includes booking to trucking and ICT. However, forwarder has to input eCargo Manifest Input Service in provider's (Ge-TS/TradeLink/Brio) system and ROCARS system for cargo transshipment via road. ROCARS is connected with e-ACI system. In this system, e-Lock and GP for tracking and tracing of goods is implemented.

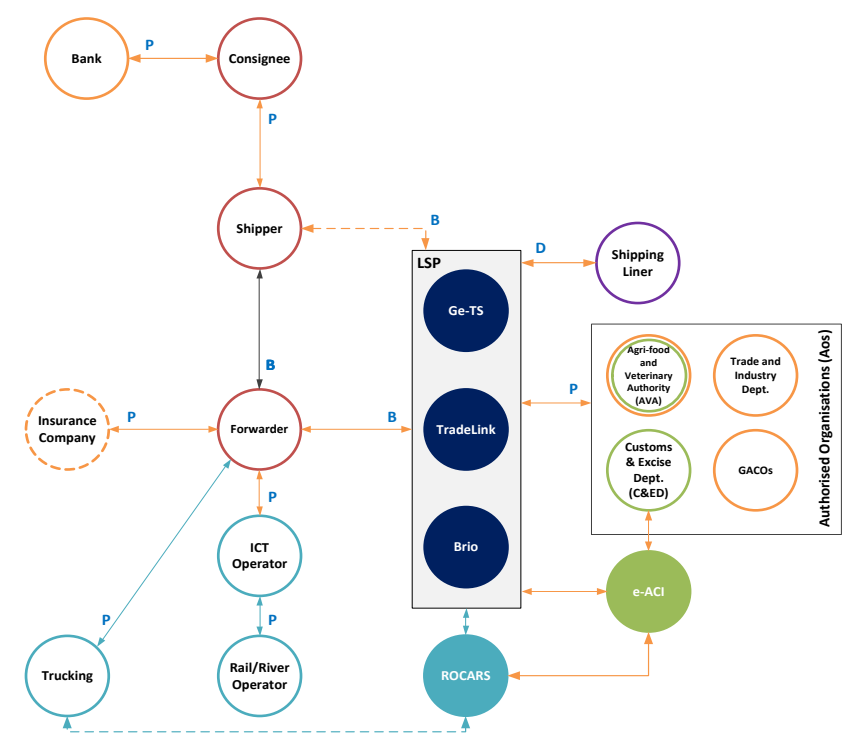

Fig. 2. IOS Architecture of Hong Kong.

\section{Netherlands}

Rotterdam is a hub seaport in Netherlands, with hinterland covering european community as a single market. Type of ICT in Netherlands is dryport as extented gate of seaport. IOS architecture in Netherlands can be seen in Fig. 3, where there is a PortBase as a single window in arrangement to seaport operator, shipping liner, ICT, GAs. PortBase is a port community system for export import.

In preparation of $\mathrm{B} 2 \mathrm{~B}$ and $\mathrm{B} 2 \mathrm{G}$ documents, user communicate with all GAs through PortBase, electronically. Here, data input only need to be done once, then the data will be used for all document processings in all GAs and other stakeholder. Thus, there is no duplication in inputting and archiving data. It simplifies coordination, because of the information sharing between GAs and other stakeholders. PortBase also has system for tracking and tracing of process, so user knows faster about the status of their document whether it is accepted or rejected and they can predict when the document is done.

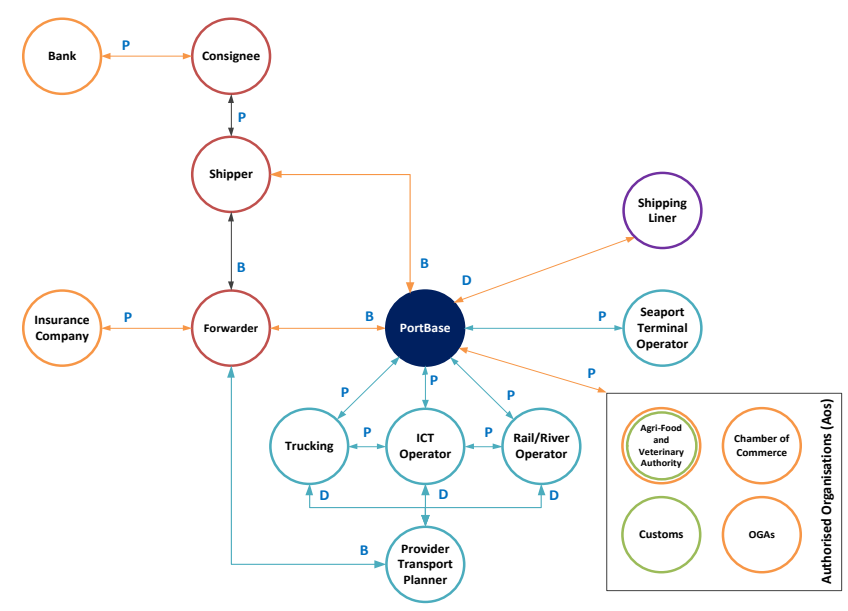

Fig. 3. IOS Architecture of Netherlands.

In processing Certificate of Origin ( $\mathrm{CO})$, document application can be done electronically through PortBase. Using modern application, user has the possibility to print all documents including stamp and signature of Chamber of Commerce. This can reduce user's administrative burden. Here, Chamber of Commerce only performs verification and validation. In case of prevention of document forgery, then all parties can verify documents online 24/7 at http://certificates.iccwbo.org/.

In customs clearance and inspection, all documents are submitted through PortBase. Export declaration requires CIQ permit. So, CIQ need to be processed beforehand. Treatment of goods is conducted at production time by manufacturer which needs to comply with the requirements from the destination country. Thus, inspection by CIQ based on database quality checks that are conducted regularly by manufacturer in production time. So, every time an exporter submits for certification, CIQ will check whether the treatments given are in accordance with the requirements of export destination country. In issuance of Phytosanitary/Veterinary Certitificate, user only receive a certificate number which will be attached on the export packaging as barcode number. Meanwhile e-Certificate will be sent directly and electronically to authority of destination country. Thus any discrepancy would immediately be detected and revised.

After CIQ permit have been accepted and goods have been delivered to inspection site, then user can submit export declaration through PortBase. In this case, Customs uses unique number EORI (the Economic Operator Registration and Identification Scheme) for all companies to communicate with Customs. Submission of export declaration must include information of safety and security. Customs use this information to perform risk analysis and goods selection for physical inspection. Companies that have been accredited as AEO (Authorized Economic Operator) is identified as trusted partner, which is incorporated in securing the global supply chain. The AEO Company receives several incentives, including reduction in Custom inspections. Customs physical inspection is conducted by scanning. Along with physical inspection, Customs performs inspection of documents (tax, certificate or license, etc.) 
In inland transportation \& handling, all processes are performed through PortBase, where land and sea transport arrangements are assisted by transport planner providers (web-based using GUI system). Application of electronic pre-notification of arrival and departure in ICT and seaport is also done in transport planner provider's system. There is also a tracking \& tracing system, which is applied very strictly. With the implementation of these two systems, driver time in terminal can be reduced. Meanwhile, inspection of compatibility between goods and its documents is carried out during Gate-In inspection in ICT or seaport, where physical inspection is conducted using X-Ray.

\section{USA}

Hinterland characteristics of USA is states, with type of ICT is a dryport as extended gate of seaport. IOS architecture in USA can be seen in Fig. 4, where there is a ACE (Automated Commercial Environment). ACE is as a single window for international trade community to submit import and export data in communicating with U.S. Customs and Broder Protection (CBP) and other government agencies. $\mathrm{ACE}$ is used to collecting, tracking, and processing necessary data information of trade. Meanwhile, communication in port community is performed through FIRST System.

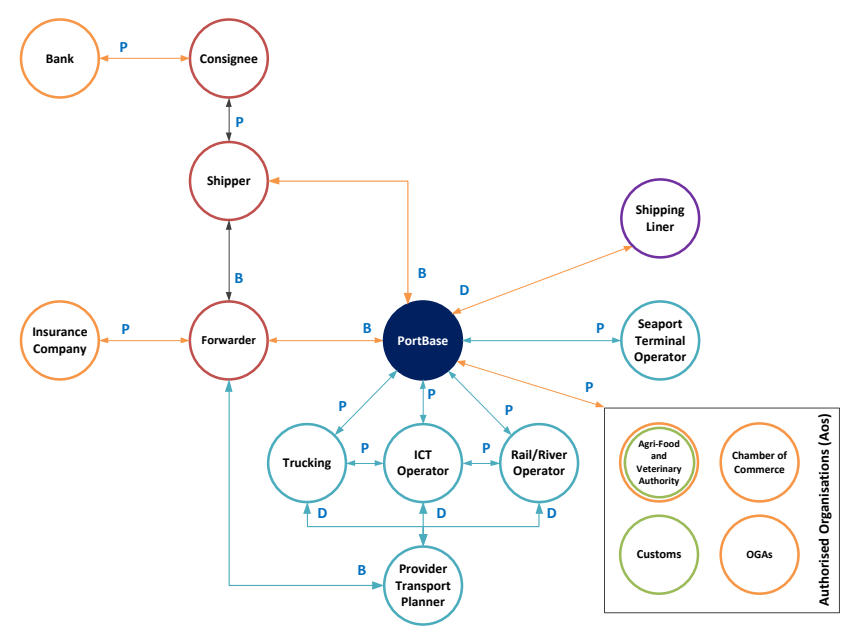

Fig. 4. IOS Architecture of USA.

In preparation of $\mathrm{B} 2 \mathrm{~B}$ and $\mathrm{B} 2 \mathrm{G}$ documents, user communicate with all partners and GAs through ACE, where all documents are shared electronically. Data input only need to be done once, then the data is used in all document processing in all GAs and other stakeholder, so there is no duplication in inputting and archiving data. It ease coordination, because there is information sharing between GAs and other stakeholders.

In customs clearance, all documents are submitted through ACE. Here, Marine Terminal Operator assist in arranging inspection and clearance by Customs. For quarantine, submission is conducted through USDA Phytosanitary Certification Issuance and Tracking (PCIT) and other local CIQ via ACE. Treatments are carried out during production and by certified cooperator, in which detailed record of treatments are annexed at the time of submitting application to Quarantine. Thus during inspection, Quarantine will do verification by taking a sample to check the treatments of the export goods. Thus, submission and inspection can be performed on the same date. In issuance Phytosanitary/Veterinary Certificate, a copy of certificate can be printed by submitted user, while the original copy only can be printed by Authorized Entities, user of Original Certificate Print Authorizations, and ACO.

In inland transportation \& handling, all processes are performed through FIRST System, which is a web portal for port community. Here, booking to shipping liner or ocean carrier is performed via FIRST System by forwarder. Then intermodal operator will contact Ocean Carrier to coordinate the goods shipment from warehouse/manufacturer to terminal, in this case Ocean Carrier will make a collaboration with drayage and railway transport companies. Here also applied pre-notification of arrival at terminal, which is a provision for receiving container via rail. Container without pre-notification will be rejected or will be examined further.

\section{DISCUSSION}

This section explains the findings obtained at best practice level of trade facilitation. Based on benchmark study, generally coordination is a central orchestration hub $(\mathrm{N}: \mathrm{M}$ or $\mathrm{N}: 1: \mathrm{M}$ ), where forwarder play as a conductor/product manager. Here, single window has a role as hub structure that allow to connect with partners. Internal application (government agencies, terminal operator and transport operator) only requires a single connection and standardized access for external partners (shipper/exporter/forwarder). This type of pattern helps in managing interdependencies, because information sharing between GAs and other stakeholders reduce the number of linkage and focus on supply chain orchestration.

In document preparation, duplication in data input and data archive is solved by single connection and single submission mechanism. Online-based application manage shared resources interdependencies, where in conventional, users need to submit physical documents at office hour while they have limited employee. Moreover, user can predict process time and monitor whether the request is accepted or rejected (with notification) using tracing and tracking of process, so user can get response faster. It helps in scheduling process in order to manage prerequisites and simultaneity constraints.

In custom clearance and inspections, custom's inspection mostly using x-Ray scanning and e-seal system. Meanwhile for quarantine inspection, there are three mechanism: (1) both inspection and treatments of goods are performed by CIQ; (2) treatments are performed by licensed cooperator and CIQ will inspect and verify the treatment based on product sample; and (3) treatments are performed during production time by manufacturer and CIQ will inspect and verify the treatment based on sample of product and database Quality Check. Requirement of applying licensed cooperator is cooperator must have certified by Quarantine. However, requirements of applying QC in verification of treatment are: exporter has to be proactive to search import requirement in destination country and QC database is open access for client. The usage of licensed cooperator in treatment process and database Quality Check in verification of treatment are carried out to change sequence of process, in order to manage prerequisites interdependencies. 
In inland transportation and handling, there are two mechanism applied: decentralized (Singapore and Hong Kong) and semi-decentralized (Netherlands and USA). Singapore and Hong Kong are applying decentralized mechanism, where forwarder/shipper contact each transport operator and arrange the shipment. However in Netherlands, internal partners (ICT operator, trucking and rail/river operator) are communicate using one single connection, PortBase. In this case, transport planners only serve as brokerage in planning and booking, but after it, hub structure is done by PortBase. Thus, here inland transportation \& handling can be described as semi-decentralized. In USA, particularly in internal partner of drayage, like Ocean Carrier, trucking companies and rail/river operator, there is a centralized coordination with Ocean Carrier act as a central orchestration. In this case, FIRST System serves as a general coordination point (information sharing) with port community as a whole, but drayage operation is coordinated by Ocean Carrier as an actor who operate long-haul. Thus, this system can be described as semi-decentralized. However, this collaboration of actor can lead to vertical integration, where it will affect cost of services whether it become cheaper or more expensive, depending on behavior of the lead actor on collaboration. Meanwhile, in term of coordination mechanism in managing prerequisites and simultaneity constraints, most countries implement pre-notification of arrival and tracking and tracing of goods.

However, challenge in implementation of such a system is not easy. Transition from conventional to online-based system is done gradually over the years. To ensure system can run smoothly, general requirements needed in implementation are:

- System in each actor involved must be integrated with single window system.

- Standardization of document format

- Reliability of network security

- System for checking authenticity of documents

- Collaboration with destination countries and connecting our single window system to ensure they can receive electronic documents (e-Doc/e-Cert).

- Reliability of database management system

- In tracking and tracing, all process and result should be recorded and reported in real time.

\section{CONCLUSION}

In order to enhance competitiveness, trade facilitation is needed to simplify process and to minimize transaction cost by simplifying procedures and associated information flows required to move goods from seller to buyer. Here, trade facilitation related to support flow of good in maritime logistics is using hub-and-spoke network, where spoke serve as extended gate of seaport (hub). Moreover in exporting goods, hinterland side involve several actors involved both from business entities and government agencies (GA). These actors have their own roles and activities that interdependent, such as shared resources, prerequisites, and simultaneity constraints. So, quality of hinterland access depends on the behavior of the actor involved [7]. Thus, it need institutional frameworks and deliberative mechanism, harmonization and simplification of business process.

This paper conducted benchmark of inter-organizational system architecture of trade facilitation in selected countries: Singapore, Hong Kong, Netherlands and USA. Focus of benchmark is on three groups of activities in export's business process: document preparations, custom clearance and inspections, and inland transportation and handling. In document preparations, mostly all benchmark countries apply single connection and single submission mechanism through single window. This mechanism manage shared resources interdependencies, so it prevent duplication in inputting and archiving data. It also ease coordination, because there is coordination sharing between GAs and other stakeholders. Moreover, tracking and tracing of process helps in scheduling process in order to manage prerequisites and simultaneity constraints. Case of Hong Kong, user can connect through three logistics provider appointed by government that act like single window. It help in minimizing monopoly and increasing competitiveness in price and services.

In custom clearance and inspections, Custom's inspection mostly using x-Ray scanning and e-seal system. Meanwhile, for quarantine's inspection, there are three mechanism applied: (1) both inspection and treatments of goods are performed by CIQ (existing system); (2) treatments are performed by licensed cooperator (USA); and (3) treatments are performed during production time by manufacturer and CIQ will inspect and verify the treatment based on sample of product and database Quality Check (Netherlands). The usage of licensed cooperator in treatment process and database Quality Check in verification of treatment are carried out to change sequence of process, in order to manage prerequisites interdependencies. These two mechanisms reduce process time.

In inland transportation and handling, there are two mechanism applied: decentralized (Singapore and Hong Kong) and semi-decentralized (Netherlands and USA). Singapore and Hong Kong are applying decentralized mechanism, where forwarder/shipper contact each transport operator and arrange the shipment. However, in Netherlands and USA there are several transport operator (actor) that collaborated, thus it called semi-decentralized. However, this collaboration of actor can lead to vertical integration, where it will affect cost of services whether it become cheaper or more expensive, depending on behavior of the lead actor on collaboration. In term of coordination mechanism in managing prerequisites and simultaneity constraints, most countries implement pre-notification of arrival and tracking and tracing of goods.

Based on benchmark study, generally coordination in export activities are central orchestration hub (N:M or $\mathrm{N}: 1: \mathrm{M})$, where forwarder play as a conductor/product manager. Here, single window has a role as hub structure that allow to connect with partners. Internal application (government agencies, terminal operator and transport operator) only requires a single connection and standardized access for external partners (shipper/exporter/forwarder). This type of pattern helps in managing interdependencies, because information sharing between GAs and other stakeholders reduce the number of linkage and focus on 
supply chain orchestration. However to implement such a system, the most challenging subjects are transition period that is done gradually over the years and the requirements needed to implement the system.

In the future papers, the conceptual model of coordination in Indonesia and its simulation of operational instrument will be carried on in order to analyze improving performance of the system. As regards these models, our aim is to operate a benchmarking in several countries that already have good logistics performance and have been implementing trade facilities which have similar hinterland with Indonesia.

\section{REFERENCES}

[1] S. Y. Chen, "Exploring digital capital of automated cargo clearance business websites," Expert Systems with Applications, vol. 38, pp. 3590-3599, 2011.

[2] K. Shintani, R. Konings, and A. Imai, "The impact of foldable containers on container fleet management costs in hinterland transport," Transportation Research Part E, vol. 46, pp. 750-763, 2010.

[3] Designing and Implementing Trade Facilitation in Asia and the Pacific, Asian Development Bank (ADB) and United Nations Economic and Social Commission for Asia and the Pacific (ESCAP), Mandaluyong City, Philippines, 2013.

[4] P. B. Turnes and R. Ernst, "A framework for transparency in international trade," Investigaciones Europeas de Direccion y Economia de la Empresa, vol. 21, pp. 1-8, 2015.

[5] C. C. Lin and S. H. Chen, "The hierarchical network design problem for time-definite express common carriers," Transportation Research Part B, pp. 271-283, 2004.

[6] C. C. Lin, "The integrated secondary route network design model in the hierarchical hub-and-spoke network for dual express service," International Journal Production Economics, vol. 123, pp. 20-30, 2010.

[7] C. Ducruet and M. Van Der Horst, "Transport integration at european ports: measuing the role and position of intermediaries," EJTIR, vol. 9, no. 2, pp. 121-142, 2009.

[8] A. Portugal-Perez and J. S. Wilson, "Export performance and trade facilitation reform: Hard and soft infrastructure," World Development, vol. 40, no. 7, pp. 1295-1307, 2012.

[9] J. Francois and M. Manchin, "Institution, infrastructure, and trade," World Development, vol. 46, pp. 165-175, 2013.

[10] J. Rudjanakanoknad, W. Suksirivoraboot, and S. Sukdanont, "Evaluation of international ports in Thailand through trade facilitation indices from freight forwarders," Procedia - Social and Behavioral Sciences, vol. 111, pp. 1073-1082, 2014.

[11] A. Erera, K. H. Kwek, C. White, and H. Zhang, "Comparison of Singapore and U.S.A Sea Cargo Container Export Processes," Logistics Institute - Asia Pacific, 2003.

[12] T. Iwanow and C. Kirkpatrick, "Trade facilitation and manufactured exports: Is Africa different?" World Development, vol. 37, no. 6, pp. 1039-1050, 2009.

[13] J. Rudjanakanoknad and W. Suksirivoraboot, "Comparison of trade facilitation at four international ports in Thailand," Procedia-Social and Behavioral Sciences, vol. 48, pp. 215-221, 2012.

[14] L. Urciuoli, J. Hintsa, and J. Ahokas, "Drivers and barriers affecting usage of e-Customs - A global survey with customs administrations using multivariate analysis technique," Government Information Quarterly, vol. 30, pp. 473-485, 2013.

[15] B. Shepherd, "Did APEC's Trade Facilitation Action Plans deliver the goods?" Journal of Asian Economics, vol. 43, pp. 1-11, 2016.

[16] K. Kumar and H. G. Van Dissel, "Sustainable collaboration: managing conflict cooperation in interorganizational systems," MIS Quarterly, pp. 279, Sep. 1996.

[17] C. Hornok and M. Koren, "Administrative barriers to trade," Journal of International Economics, vol. 96, pp. S110-S122, 2015.

[18] N. Lang, H. M. Moonen, F. J. Srour, and R. A. Zuidwijk, "Multi Agent Systems in logistics: A Literature and State-of-the-art Review," ERIM Report Series Research in Management, Erasmus Research Institute of Management, Rotterdam, 2008.

[19] Doing Business 2013, 10th ed., World Bank and International Finance Corporation, Washington, DC, 2013.

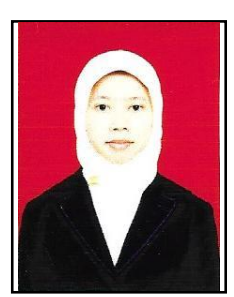

Sita A. Sholihah earned her bachelor degree in mathematics from Padjajaran University, Indonesia and her master degree in industrial engineering from Bandung Institute of Technology, Indonesia. She is currently working on a doctoral research at Department of Industrial Engineering, Bandung Institute of Technology, Indonesia. Her research focuses on inter-organizational system, maritime logistics and agent-based system. During her time in pursuing doctoral, she had also worked for Center for Logistics and Supply Chain Studies - ITB, Bandung.

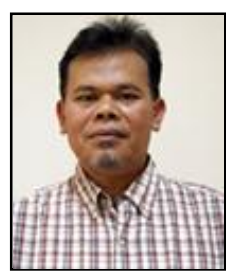

Senator Nur Bahagia is a professor of industrial system and techno-economics and Chairman of Center for Logistics and Supply Chain Studies (CLoCS) at Bandung Institute of Techonology, Indonesia. He received his master in IAE - L'Universite d'Aix Marseille III, France and his $\mathrm{PhD}$ at the same university. His research concentrate on production system, and logistics and supply chain.

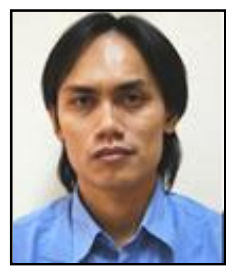

Andi Cakravastia received his master in industrial engineering at Bandung Institute of Technology, Indonesia and his $\mathrm{PhD}$ at Hiroshima University, Japan. He is currently an associate professor in Department of Industrial Engineering, Bandung Institute of Technology, Indonesia. His field of interest are operation research and decision science, system simulation, and supply chain system design and development

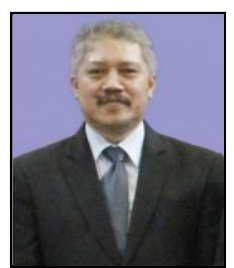

TMA Ari Samadhi received his master in University of New South Wales - Australia and his $\mathrm{PhD}$ at the same university. He is currently an associate professor in Department of Industrial Engineering, Bandung Institute of Technology, Indonesia. His research focus on production planning and control design, distributed production system development, manufacturing system - supply network integration development, and quality management system development. 